\title{
NATURAL ANTIOXIDANT INGREDIENT FROM BY-PRODUCTS OF FRUITS
}

\author{
${ }^{1}$ EI-Baroty, G.S., ${ }^{2}$ M.F. Khalil and ${ }^{2}$ S.H.A. Mostafa \\ ${ }^{1}$ Department of Biochemistry, Faculty of Agriculture, Cairo University, Giza, Egypt \\ ${ }^{2}$ Institute of Food Technology, Agriculture Research Centre, Giza, Egypt
}

Received 2014-01-19; Revised 2014-01-25; Accepted 2014-03-22

\begin{abstract}
The contents of total phenolics compounds and their phenolic constituents were quantified in organic and aqueous of four varieties (Zebdia, Sukkari, taimor and Hindi) of mango (Mangifera indica L.), seeds pulp and kernel, one varieties of pomegranate (Punica ranatum L., peel) and peanut (Arachis hypogaea L., Giza 6, shell) by-products. The antioxidant activities of all by products extracts were assessed by five antioxidant methods as well as by rancimate test. The total Phenolic content of aqueous and organic extracts of among all mango varieties, pomegranate and peanut shell showed the content values ranging from 71.06 to $124.18 \mathrm{mg} / 100 \mathrm{~g}, 95.07$ to 124.18 $\mathrm{mg} / 100 \mathrm{~g}$ and 41.64 to 71.06 , respectively. Nineteen phenolic compounds were identified by High Performance Liquid Chromatography (HPLC) among all mango varieties, of which vanillic acid, benzoic acid and mangiferin were occurred in high amounts. The major phenolic compounds were detected in pomegranate and peanut shell were chlorogenic and gallic and caffeic (24.42\%), respectively. All fruits by products were exhibited remarkable antioxidant activity, with various degrees in all tested methods. However, among all by-products extracts, organic extract had higher antioxidant than that aqueous extracts toward all antioxidant tested. Mango kernel peel and pomegranates showed high radical scavenging activity, which could be compared with the synthetic antioxidants Butylated Hydroxyanisol (BHA). However, all by-products extracts exhibited high inhibit effect against the lipid peroxidation of sunflower oil (at $100^{\circ} \mathrm{C}$ ) as assessed by rancimat methods. However, this antioxidant activity was found to be strong significant correlation with phenolic contents $(\mathrm{p}<0.05)$ in by-product extracts. It can be thus concluded that varied varieties of mango, pomegranate and peanut by-products, although it constitutes the part of the fruits, it is valuable parts due to its antioxidant activities, it can be used safely in the edible oil industry and cosmetics to delay its oxidation. It can be applied in other food industries as a natural antioxidant instead of synthetic antioxidants. Further study should be carried out to identify the predominant phenolics responsible for the antioxidant activity of by product extracts.
\end{abstract}

Keywords: High Performance Liquid Chromatography (HPLC), Butylated Hydroxy Anisol (BHA)

\section{INTRODUCTION}

In Egypt, the food and agricultural industries produce large quantities of waste and/or by-products, causing a biggest serious disposal problem. In particular, Egyptian economy is largely based on Corresponding Author: El-Baroty, G.S., Biochemistry Department, Faculty of Agriculture, Cairo University, Giza, Egypt

agricultural sector and where the farming practice is very intensive. However, the most of agro-wastes are either allowed to decay naturally on the fields or are burned or used as low quality compost or animal feed without segregation or significant treatment. However, burned of wastes caused black cloud 11 AJABS 
phenomena and lead to biggest air pollutants. Therefore, from view point of economic and environmental, treated of agricultural wastes and agro-industrial to produce high value by-products is desirable (Nandeesh et al., 2011; Elleuch et al., 2011). For instant, the main by-products of processing mangos (Mangifera indica L.) are the kernel, peel and the seed, which represent approximately $35-60 \%$ of total fruit weight (Larrauri et al., 1996), these parts are not currently being utilized commercially in any way, though a large quantity is generated as waste (20-25\% of total fruit weight) during mango processing thus, contributing to pollution (Berardini et al., 2005; Dorta et al., 2012). However, these agro by-product are contain large amount of bioactive compounds which act as antimicrobial and antioxidant activities and they have potential nutritional and therapeutic effect that could be used in different sectors such as pharmaceutical, cosmetic and food industries (Demiray et al., 2009).

The main by-products of processing mangos (Mangifera indica L.) are the peel and the seed, which represent approximately 35-60\% of the fruit (Larrauri et al., 1996) However, mango peel as a byproduct of mango processing industry are containing high quantity of bioactive compounds and enzymes such as protease, peroxidase, polyphenol oxidase, carotenoids, vitamins $\mathrm{C}$ and $\mathrm{E}$, dietary fibers, enzymes and carbohydrate (Ajila et al., 2007a; $2007 \mathrm{~b}$ ). In general, the most of bioactive compound in by-products are identifies as phenolic, tannins, carotenoids, glycosides, tannins, fatty acids, organic acids, vitamins, pectin and others compounds (Jawad et al., 2013; Djilas et al., 2009).

Nowadays, the important sources of a wide variety of bioactive compounds are antioxidants. It has been known that under stress conditions, Reactive Oxygen Species (ROS) and free radicals are produced in an extensive range during metabolism in living organisms. In human, the insufficiency of antioxidant defense mechanisms is associated to chronic diseases such as diabetes, cancer, cardio-vascular and neurodegenerative diseases (Costa et al., 2009). Recent reports demonstrated that by-products of vegetables and fruits could be act as a good source of natural antioxidants due to the presence of high levels of carotenoids, tocopherols, flavonoids and ascorbic acid. In many reports, strong epidemiological evidence shows that these compounds may help to protect the human body against damage by reactive oxygen species (Jahangir et al., 2009). In many fruits, leaves, flowers, stems and roots of plants, contain significant amounts of bioactive compounds, which provide desirable health benefits beyond basic nutrition.

Several researches have focused on the health benefits of consumption of mangoes, pomegranate fruit and peanuts claiming these as natural sources of bioactive compounds with highly promising antioxidant and anti-inflammatory and cancer (Maisuthisakul, 2009; Ribeiro-Junior et al., 2008; Costa et al., 2009). The objectives of the current study were to investigate the phenolic content and their constituents in organic and aqueous extracts in byproducts of four varieties of mango and one variety of pomegranate and peanut fruits. Also, antioxidant activities of all by products extracts were evaluated.

\section{MATERIALS AND METHODS}

\subsection{Plant Material}

Four varieties (Zebdia, Sukkari, Timor and Hindy) of mango, one variety of pomegranate (Punica granatum L.) and one variety of peanut (Arachis hypogaea L., Giza 6) were obtained from Agricultural Research Center (ARC, Giza)

\subsection{Chemical Reagents}

All solvents (HPLC grade), 1,1-diphenyl picrylhydrazyl radical (DPPH), Butylated Hydroxytoluene (BHT), linoleic acid, $\beta$-carotene, 2,2Azinobis-(3-ethyle Benzothiazoline-6- Sulphonate (ABTS), ammonium per sulphate and gallic acid and other phenolic standard use throughout the study were purchased from Sigma-Aldrich Company (St. Louis, MO, USA). All other chemicals (analytical grade) were obtained from Merck CO., (Germany).

\subsection{Preparation of Plant Materials}

Mango fruits were washed and the peels were handily removed from the fruits, also seeds, shell of fibrous endocarp were separated to kernel and pulp, the shell of peanut were separated by hand and also shell of pomegranate were separated from eaten parts by hand. All by-products $(100 \mathrm{~g})$ were washed and dried in shaded area at room temperature and then chopped with electric mixer (Moulinex, 1600 watt) and obtained powder materials were stored in brawn containers. 


\subsection{Extraction of Active Compounds}

\subsubsection{Organic Extract (OE)}

Bioactive compounds were extracted by socking of dried by-products materials of four varieties mango, pomegranate and peanut shell (each, 50 grams), in solvent mixture 1:1 methanol: Dichloromethane $(\mathrm{V} / \mathrm{V}, 1: 1)$, with volume: Byproducts ratio $(1: 10, \mathrm{w} / \mathrm{v})$ for $24 \mathrm{~h}$ at room temperature. The crude organic by-products extracts were filtrated through Wattman filter paper No 1 and evaporated under reduced pressure to small volume $(15 \mathrm{~mL})$ and flushed with nitrogen gas, then stored at $-20^{\circ} \mathrm{C}$ prior to analysis.

\subsubsection{Aqueous Extracts (AE)}

The residual material after filtrated from $\mathrm{COE}$ was dried at room temperature and socked deionized water with volume: By-products ratio $(1: 50, \mathrm{w} / \mathrm{v})$ for $24 \mathrm{~h}$ at room temperature. The crude Aqueous by-products Extracts (AE) were filtrated through Wattman filter paper No 1 and dried with freeze-dried, the powder materials then were stored at $-20^{\circ} \mathrm{C}$ prior to analysis.

\subsection{Determination of Total Phenolic Compounds}

The concentration of total phenolic compounds in by-product was determined by spectrophotometrical method at $765 \mathrm{~nm}$, using the Folin-Ciocalteu reagent (Spanos and Wrolstad, 1990). Gallic acid standard solutions were prepared at serious concentration (0.0$0.5 \mathrm{mg} \mathrm{mL}^{-1}$. The concentration of total phenolic compounds in the extracts was determined by comparing the absorbance of the extract samples to that of the gallic acid standard solutions. All samples were determined in duplicate. Total Phenolic Content (TPC) was expressed as mg Gallic Acid Equivalents (GAE) per g dry by products.

\subsection{Antioxidant Assays}

\subsubsection{DPPH Scavenging Assay}

The scavenging activity of by-product extracts toward DPPH • free radical was determined by the Brand-Williams et al. (1995) method. The absorbance was assayed by decreasing absorbance at $517 \mathrm{~nm}$, for $30 \mathrm{~min}$. Total antioxidant capacity was calculated relative to the reactivity of BHT under the same conditions and the results were shown as ppm. The ability to scavenge DPPH• was calculated as:
DPPH radical scavenging activity $=\{($ Abs controlAbs sample $) /($ Abs control $)\} \times 100$

\subsubsection{ABTS Assay}

The antioxidant activities of by-product extracts toward stable ABTS+ radical cation were determined according to the method of $\operatorname{Re}$ et al. (1999). Absorbance readings at $734 \mathrm{~nm}$, the calculation of the radical inhibition percentage was made using the following formula: (\%) radical inhibition radical scavenging activity $=\{(\mathrm{Abs}$ control-Abs sample $) /($ Abs control $)\} \times 100$

\subsubsection{Ferric Reducing Power Assay (FRAP)}

The ferric reducing power of the extracts was carried out as described by Lim and Murtijaya (2007), the absorbance was recorded at $700 \mathrm{~nm}$ against $\mathrm{FeSO}_{4}, 7 \mathrm{H}_{2} \mathrm{O}$ as the reference standard for preparation of calibration curve.

\subsection{4. $\beta$-Carotene-Linoleic Acid Bleaching Assay}

The procedure is based on a modified method of Farag et al. (1989) was used to determine antioxidant activity was measured at $470 \mathrm{~nm}$ against a blank (1\% Tween-20 Solution). All samples were done in triplicates.

\subsection{Fraction and Identification of Phenolic Compounds by HPLC}

Phenolic compounds were qualitative analyses by HPLC according to the Goupy et al. (1999) method. After samples preparation $\left(10 \mathrm{mg} \mathrm{mL}^{-1}\right)$, was injected into HPLC Hewlled Packared (series 1050) equipped with auto-sampling injector, solvent degasser, Ultraviolet (UV) detector set at $280 \mathrm{~nm}$ and quarter HP pump (series 1050). The column temperature was maintained at $35^{\circ} \mathrm{C}$. Gradient separation was carried out with methanol and acetonitrile as a mobile phase at flow rate $1 \mathrm{~mL}$ min $\min ^{-1}$. phenolic acid standard (Sigma Aldrich Co., purity $0.96 \%$ ) was dissolved in a mobile phase and injected into HPLC. Retention time and peak area were used to calculation of relative area percentage (\%) data analysis of Hewllet Packared software.

\subsection{Rancimat Test (Oxidation Stability Index)}

This test assumes that thermo oxidative changes at $100^{\circ} \mathrm{C}$ and may provide good information shelf life, rancidity development and oxidative resistance of oils and foods containing them at normal temperature. A Metroham 679 rancimat instrument 
(Herisau, CH-9101, Switzerland) connected to a receiving electrochemical cell was used in measuring the oxidative stability of oil at $100^{\circ} \mathrm{C}$ as describe by (Labulbi and Bruttel, 1986; Gordon and Mursi, 1994). Air rate $20 \mathrm{~mL} \mathrm{~min}^{-1}$ was injected into an oil sample $(5 \mathrm{~g})$ mixed with extracts dissolved in diethyl ether in concentration $(0.2-0.4$ and $0.5 \mu \mathrm{L})$ in a glass cylinder. The tangent method was applied to determine the conductivity. A curve of oil oxidation stability was calculated by using hour of induction periods which showed in rancimat chromatogram. A longer induction period (as indicate by time in $\mathrm{hr}$ ) indicated higher oxidative stability.

\section{RESULTS}

\subsection{Total Phenolic Contents}

As shown in Table 1, it can be observed that a wide range of total phenolic contents among all by products ranged 71.06 to $124.18 \mathrm{mg} / 100 \mathrm{~g}$ in organic extracts by-product while it was from 41.65 to 95.07 in aqueous (lyophilized) by-products. Pomegranate by-product recorded the highest phenolic levels in both the organic $(124.18 \mathrm{mg} / 100 \mathrm{~g})$ and aqueous $(95.07 \mathrm{mg} / 100 \mathrm{~g})$ extracts. In contrast, peanut shell by-product represents the lowest values in either organic (71.06 $\mathrm{mg} / 100 \mathrm{~g})$ or aqueous (41.64 $\mathrm{mg} / 100 \mathrm{~g}$ ) by-product extracts.

Also, results in Table 2 showed that total phenolic content in organic extract seed pulp of mango present in highest values among all parts of mango varieties. They found to be $112.01,114.18$, 104.98 and $98.72 \mathrm{mg} / 100 \mathrm{~g}$ for zebdia, socary, hindy and timor. On the other hand, aqueous extracts of mango seed pulp were found in lower values than organic extracts; they were $84.18,82.13,78.11$ and $72.17 \mathrm{mg} / 100 \mathrm{~g}$, respectively.

\subsection{Antioxidant Activity}

Table 2 shows antioxidant capacity of organic and aqueous by-products of four varieties of mango and one variety of peanut and pomegranate as assessed by four antioxidant assays: DPPH, ABTS, inhibition of bleaching $B$-carotene/linoleic acid and FRAP. For instant, pomegranate shell represents the highest antioxidant activity for organic (96.0, 97.62, 78.13 and $94.46 \%$ ) or aqueous $(92.0,91.79,72.39$ and $89.51 \%$ ) extracts. Peanut shell in both extracts represents the lowest values of the DPPH and ABTS scavenging activity and inhibition of $\beta$-carotene linoleic acid assays. In FRAP assay, the data for all by-product extracts showed that mango seed kernel had lowest antioxidant capacity zebdiea (FRAP = 4.32) variety, while taimor variety had the highest value $($ FRAP $=12.46)$. Thus, the results of total phenolic content in the studied samples was correlated and positively with their antioxidant capacity among all antioxidant assays (DPPH, ABTS, bleaching Bcarotene/linoleic acid and FRAP).

\subsection{Identification of Phenolic Compounds}

Table 3 shows phenolic constituents (area \% of total phenolics) of organic extracts by-products analyzed byHPLC. In organic extract of mango seed pulp, major phenolic compounds in zebdeia variety could be use a marker for characterized of mango seed pulp were $27.14 \%$ ferulic acid, $24.75 \%$ vanillic acid, mangiferin (13.56\%), chlorogenic acid (6.08\%), caffeic (5.26\%) and gallic acid $(3.73 \%)$. While in soccary variety the most abundant phenolic constituents were caffeine (17.83\%), vanillic acid (13.11\%), ferulic acid (11.47\%), coumarin $(6.62 \%)$ and gallic acid $(6.52 \%)$.

Also, it interesting results that in hindi variety vanillic acid (11.68\%), protocatechin (11.06\%), catichol $(9.92 \%)$, chlorogenic acid $(8.88 \%)$, caffeine $(8.2 \%)$ and Mangiferin $(7.7 \%)$ were identified as major constituents. In timor variety were characterized by relative high amounts of vanillic acid $(15.67 \%)$, caffeine $(15.25 \%)$, Benzoic acid $(13.18 \%)$ and mangiferin $(11.31 \%)$. These results revealed that mango seed pulp by products were characterized by present of vanillic acid, ferulic acid, caffeine, mangiferin and chlorogenic acid as major phenolic compounds with varied concentrations.

Phenolic compounds in mango seed kernel (MSK) had a similar profile that observed among all varieties of seed pulp. In zebdeia variety, gallic $(17.5 \%)$ acid, chlorogenic (11.14\%), ferulic $(17.42 \%)$ and $12.66 \%$ p-OH- benzoic acid (12.66\%) were identified as major constituents. On the other hand, MSK organic extracts of soccary was characterized by present of gallic acid (17.36\%), vanillic acid $(11.88 \%)$, caffein $(9.77 \%)$ and mangiferin $(5.09 \%)$ in relative high amounts. Hindy variety had high amounts of benzoic acid $(31.93 \%)$, caffeic acid $(19.02 \%)$, mangiferin (12.20\%) and gallic acid (10.47\%). While in taimor MSK, pyrogallol 43.23\% and $13.57 \%$ gallic acid was the most abundant phenolic compounds. As showed in Table 4, nineteen phenolic compounds in organic acid of pomegranate peel were identified by HPLC, of which chlorogenic $(12.99 \%)$, caffeic acid, catechol $(7.50 \%)$ and ellagic $(7.59 \%)$ were percent in high amounts. 
El-Baroty, G.S. et al. / American Journal of Agricultural and Biological Sciences 9 (3): 311-320, 2014

Table 1. Phenolic content in organic and aqueous extracts of four fruit by-products

\begin{tabular}{|c|c|c|c|}
\hline \multirow[b]{2}{*}{ Fruits } & \multicolumn{3}{|c|}{ Phenolic content (mg/100gm DW) } \\
\hline & Variety & Organic methanolic extract & Aqueous extract \\
\hline Pomegranate peel & ----------- & 124.18 & 95.07 \\
\hline Peanut shell & ------------- & 71.06 & 41.65 \\
\hline \multirow[t]{4}{*}{ Mango seed kernel } & Zebdeia & 92.12 & 58.77 \\
\hline & Socary & 85.14 & 62.03 \\
\hline & Hindi & 89.16 & 59.82 \\
\hline & Timor & 79.52 & 54.33 \\
\hline \multirow[t]{4}{*}{ Mango seed pulp } & Zebdeia & 112.01 & 84.18 \\
\hline & Socary & 114.18 & 82.13 \\
\hline & Hindi & 104.98 & 72.17 \\
\hline & Timor & 98.72 & 78.11 \\
\hline
\end{tabular}

Table 2. Antioxidant activity (\% inhibition percentage) of organic and aqueous extract of four fruit by-products

\begin{tabular}{|c|c|c|c|c|c|c|c|c|}
\hline \multirow[b]{2}{*}{ Fruits } & \multirow[b]{2}{*}{ Variety } & \multicolumn{2}{|c|}{ DPPH (\%) } & \multicolumn{2}{|c|}{ ABTS $(\%)$} & \multirow{2}{*}{$\begin{array}{l}\text { Inhibition of } \\
\text { bleaching } \beta \text {-carotene } \\
\text { linoleic acid } \\
\text { Organic }\end{array}$} & \multicolumn{2}{|c|}{ FRAP (\%) } \\
\hline & & Organic & Aqueous & Organic & Aqueous & & Organic & Aqueous \\
\hline Pomegranate peel & ------------- & 96 & 92 & 97.62 & 91.79 & 78.13 & 94.46 & 89.51 \\
\hline Peanut shell & ------------- & 81 & 70 & 70.12 & 53.13 & 39.01 & 32.24 & 29.62 \\
\hline & Zebdeia & 89 & 79 & 70.51 & 61.83 & 43.11 & 23.6 & 13.32 \\
\hline & Socary & 83 & 72 & 82.63 & 55.09 & 42.12 & 17.25 & 4.32 \\
\hline & Hindi & 86 & 82 & 79.12 & 73.24 & 43.11 & 14.71 & 6.15 \\
\hline & Timor & 88 & 71 & 76.14 & 60.3 & 39.22 & 12.46 & 9.57 \\
\hline 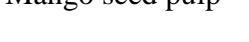 & Zebdeia & 93 & 87 & 91.34 & 77.89 & 56.02 & 52.02 & 19.11 \\
\hline & Socary & 95 & 75 & 89.04 & 75.32 & 59.18 & 93.71 & 25.41 \\
\hline & Hindi & 94 & 82 & 89.05 & 72.08 & 63.11 & 88.29 & 72.66 \\
\hline
\end{tabular}

Table 3. Phenolic constituents (\%, of total area) of organic extract of four fruits by-product

\begin{tabular}{|c|c|c|c|c|c|c|c|c|c|c|}
\hline \multirow[b]{3}{*}{ Components } & \multicolumn{6}{|c|}{ By-products extracts } & & & & \\
\hline & \multirow{2}{*}{$\begin{array}{l}\text { Pomegranate } \\
\text { peel }\end{array}$} & \multirow{2}{*}{$\begin{array}{l}\text { Peanut } \\
\text { shell }\end{array}$} & \multicolumn{4}{|c|}{ Mango seed kernel } & \multicolumn{4}{|c|}{ Mango seed pulp } \\
\hline & & & Zebdeia & Soccary & Hindi & Taimor & Zebdeia & Soccary & Hindi & Taimor \\
\hline Syringic acid & 0.031 & ------ & ----- & 0.172 & ------ & 0.045 & ------ & ------ & 0.03 & ------- \\
\hline Pyrogallol acid & 4.661 & 5.457 & 3.748 & 2.091 & ------- & 43.23 & 1.46 & 3.08 & 2.24 & -------- \\
\hline Gallic acid & 7.955 & 19.902 & 17.556 & 7.36 & 10.474 & 13.541 & 3.73 & 6.5 & 7.13 & 7.89 \\
\hline Gentistic acid & 4.532 & 5.361 & ------ & 3.562 & 0.635 & 1.818 & ----- & ----- & 2.01 & ----- \\
\hline 3-Hydroxy tyrosol & 8.857 & ----- & 3.269 & 3.941 & 2.118 & -------- & 0.49 & 0.51 & ----- & 1.16 \\
\hline Protocatechuic acid & 4.073 & ------ & 3.31 & 9.717 & 2.011 & 6.342 & 0.85 & 2.84 & 11.06 & 5.18 \\
\hline Catechein & ----- & ------ & 1.73 & 3.073 & 2.629 & 2.14 & 0.93 & 1.93 & ----- & 2.88 \\
\hline Catechol & 7.506 & 11.69 & 2.65 & 6.912 & 3.624 & 2.035 & 0.81 & ------ & 9.92 & -------- \\
\hline Chlorogenic & 12.911 & ----- & 11.142 & 6.577 & ------- & 3.374 & 6.08 & 12.65 & 8.88 & ------- \\
\hline Benzoic acid & 2.793 & ------ & ------ & 2.563 & 31.932 & 1.064 & 3.6 & 4.79 & 1.7 & 13.18 \\
\hline Caffeic acid & 6.399 & 24.418 & 2.521 & 6.512 & 19.024 & 2.412 & 5.26 & 3.5 & 9.54 & 6.01 \\
\hline Mangeferin & 3.769 & -------- & 2.185 & 5.096 & 12.205 & 3.966 & 13.56 & 1.19 & 7.71 & 11.31 \\
\hline Vanillic & 5.755 & 4.432 & 4.515 & 11.884 & ------ & 2.17 & 24.75 & 13.11 & 11.68 & 15.67 \\
\hline Caffein & 10.439 & ------- & 17.428 & 9.276 & ------ & 4.002 & ----- & 17.83 & 8.21 & 15.25 \\
\hline Ferulic acid & 2.214 & 10.383 & 12.668 & 4.569 & ------ & 3.84 & 27.14 & 11.47 & 5.71 & 10.59 \\
\hline P-Hydroxy Benzoic & 1.604 & ------- & 4.851 & 4.678 & 4.835 & 2.33 & 2.68 & 2.43 & 1.73 & 1.19 \\
\hline Salycilic acid & 4.826 & 9.979 & 2.477 & 2.789 & ------ & 3.34 & ------ & 2.69 & 2.4 & ------- \\
\hline Ellagic acid & 7.597 & ------- & 5.704 & 3.724 & 4.133 & 2.035 & 5.21 & 6.07 & 5.26 & 5.15 \\
\hline Coumarin & 2.986 & 5.49 & 2.257 & 1.497 & 3.413 & 1.18 & 2.73 & 6.62 & 2.38 & 2.68 \\
\hline Cinnamic acid & 0.96 & 3.439 & 1.997 & 3.999 & 2.961 & 1.098 & 0.61 & 2.72 & 2.31 & 1.78 \\
\hline
\end{tabular}


El-Baroty, G.S. et al. / American Journal of Agricultural and Biological Sciences 9 (3): 311-320, 2014

Table 4. Oxidative stability of sunflower oil (hr) treated with four fruit by-products as tested by rancimat method

\begin{tabular}{|c|c|c|c|c|c|c|c|c|c|c|c|c|c|c|c|c|}
\hline \multirow{3}{*}{$\begin{array}{l}\text { Extracted } \\
\text { antioxidant }\end{array}$} & \multicolumn{8}{|c|}{ Oxidative stability at $100^{\circ} \mathrm{C}$ organic mango seed kernel } & \multicolumn{8}{|c|}{ Oxidative stability at $100^{\circ} \mathrm{C}$ organic mango seed kernel } \\
\hline & \multicolumn{2}{|c|}{ Zebdia } & \multicolumn{2}{|c|}{ Soccary } & \multicolumn{2}{|c|}{ Hindy } & \multicolumn{2}{|c|}{ Taymor } & \multicolumn{2}{|c|}{ Zebdia } & \multicolumn{2}{|c|}{ Soccary } & \multicolumn{2}{|c|}{ Hindy } & \multicolumn{2}{|c|}{ Taymor } \\
\hline & I.P. & R.S. & I.P. & R.S. & I.P. & R.S. & I.P. & R.S. & I.P. & R.S. & I.P. & R.S. & I.P. & R.S. & I.P. & R.S. \\
\hline Control & 11.0 & 1.00 & & & & & & & & & & & & & & \\
\hline 0.01 & 11.2 & 1.02 & 11.0 & 1.00 & 11.2 & 1.02 & 11.4 & 1.04 & 15.6 & 1.42 & 16.4 & 1.490 & 13.4 & 1 & 14.0 & 1.27 \\
\hline 0.02 & 12.2 & 1.11 & 11.7 & 1.06 & 13.3 & 1.21 & 11.5 & 1.05 & 20.6 & 1.87 & 16.9 & 1.530 & 13.9 & 1 & 14.4 & 1.31 \\
\hline \multirow[t]{3}{*}{0.05} & 12.4 & 1.13 & 13.0 & 1.16 & 14.0 & 1.27 & 12.0 & 1.09 & 21.7 & 1.97 & 39.3 & 13.57 & 15.9 & 1 & 15.4 & 1.40 \\
\hline & & & Aque & us $m a$ & ggo see & d pulp & & & $\begin{array}{l}\text { Aque } \\
\text { pome }\end{array}$ & $\begin{array}{l}\text { gus } \\
\text { granate }\end{array}$ & $\begin{array}{l}\text { Meth } \\
\text { pome }\end{array}$ & lic & $\begin{array}{l}\text { BHT } \\
0.02 \text { a }\end{array}$ & $\begin{array}{l}1, \\
0.05)\end{array}$ & & \\
\hline & $\begin{array}{l}\text { I.P. } \\
11.0\end{array}$ & R.S. & I.P. & R.S. & I.P. & R.S. & I.P. & R.S. & I.P. & R.S. & I.P. & R.S. & I.P. & R.S. & & \\
\hline 0.01 & 14.5 & 1.30 & 12.9 & 1.17 & 14.3 & 1.30 & 13.0 & 1.14 & 11.9 & 1.08 & 14.4 & 1.31 & 14.2 & 1 & & \\
\hline 0.02 & 11.3 & 1.27 & 12.7 & 1.15 & 12.6 & 1.15 & 12.0 & 1.08 & 10.4 & 0.94 & 15.6 & 1.42 & 14.8 & 1 & & \\
\hline 0.05 & 7.20 & 0.65 & 6.90 & 0.63 & 8.90 & 0.76 & 7.7 & 0.70 & 8.70 & 0.79 & 16.1 & 1.46 & 15.0 & 1 & & \\
\hline
\end{tabular}

I.P., Induction period (hr) by rancimat test

R.S., relative stability (treated/control sample)

\subsection{Rancimat Assays}

The oxidative stability of sunflower oil (control) were assesses by added of organic $(0.01,0.02$ and $0.05 \%)$ and aqueous $(0.01,0.02$ and $0.05 \%)$ extracts of pomegranate, peanut and four varieties zebdia, succary, hindi and timor, of mango seed kernel and mango seed pulp using rancimat method (Hasenhuettl and Wan, 1992) at $100^{\circ} \mathrm{C}$ and the results represented in Table 4. Organic mango seed kernel extracts results indicated a slight increasing in induction periods of sunflower seed oil if compared its induction period with the organic mango seed pulp extracts. Organic mango seed kernel extracts recorded $12.4,13.0,14.0$ and $12.0(\mathrm{~h})$ induction period when organic mango seed kernel extracts of zebdeia, succary, hindy and timor varieties were added at level $(0.05 \%)$ to sunflower oils, with also a slight relative stability 1.13 , 1.18, 1.27 and 1.09, respectively. As for Butylated Hydroxy Anisol (BHA) as food standard antioxidants (maximum used level for adding was $175 \mathrm{mg} \mathrm{Kg}^{-1}$, CODEX STAN 210-1999), showed the induction period for sunflower of $14.2,14.8$ and $15.0 \mathrm{~h}$, when added at $0.01,0.02$ and $0.05 \mathrm{mg} \mathrm{g}^{-1}$, respectively. Interesting good observation, was recorded for organic pomegranate by product extract whereas, it represent $14.4,15.6$ and $16.1(\mathrm{~h})$ induction period when tested at levels $0.01,0.02$ and $0.05 \mathrm{mg} \mathrm{g}^{-1}$ with relative stability $1.31,1.42$ and $1.46(\mathrm{~h})$, respectively.

As for aqueous mango seed pulp and pomegranate extracts which added to sunflower seed oil, results showed unequal trend differ than the effect of mango seed pulp extract. Whereas at 0.01 or $0.02 \mathrm{mg} \mathrm{g}^{-1}$ level of aqueous extracts, it was found that increase in induction period for 0.01 level as $14.5,12.9,14.3$ and
$12.6 \mathrm{~h}$ ) for aqueous mango seed pulp extracts and $11.9 \mathrm{~h}$ for pomegranate by product, also at 0.02 level aqueous mango seed pulp recorded lower induction period for the four varieties of mango $(11.3,12.7,12.6$ and $11.9 \mathrm{~h}$. respectively), these values were higher than that of control. While, for pomegranate aqueous extract was $(10.4 \mathrm{~h})$ lower than the control. As for level $(0.05)$ of aqueous mango seed pulp the trend of stability take decrease in the induction periods which recovered 7.2, 6.9, 8.9 and 7.7 (h) for zebdeia, succary, hindy and timor varieties. Similar trend was obtained for aqueous pomegranate extract at level $(0.05 \%)$ it recorded 8.7 (h) with relative stability 0.79 . Thus the aqueous of the four varieties of mango seed pulp and pomegranate were improving the stability of sunflower seed oil at level of 0.01 and it is considerable active as antioxidative effectiveness. The relative lower stability of sunflower oil caused by aqueous extracts of mango and pomegranate at 0.05 levels may due to the increase of concentration of additive act as pro-oxidant or antagonistic effect (Olcott and Einest, 1957). Here again organic-extract of tested by-products showed potential activities as antioxidant agents compared to standard synthetic antioxidants BHA. The natural antioxidant is preferred over synthetic antioxidants to minimize adverse effects on humankind.

\section{DISCUSSION}

The results of total phenolic in mango by-products showed that mango seed pulp contain higher total phenols values in all varieties studied than mango seed kernel. Soong and Barlow (2004) reported that phenolic 
contents of in mango seed was $117.0 \mathrm{mg}$ Gallic acid equivalent/g, while mango pulp had $2.4 \mathrm{mg}$ Gallic acid equivalent/g. On the other hand, Ribeiro-Junior et al. (2008) found that the peel and seed of mango had a total phenolic content of 57.2 and $82.45 \mu \mathrm{g} \mathrm{g}^{-1}$ of dry matter. These values were 4.6 and 7.3 times higher than those in the pulp, respectively. In mango seed kernel by-products, it found to be $92.12,85.14,89.16$ and $79.52 \mathrm{mg} / 100 \mathrm{~g}$ dry weight for zebdia, socary, hindy and timor varieties in organic extracts, respectively. While it was found in lower values in aqueous extracts, it represents 58.77, $62.03,59.82$ and $54.33 \mathrm{mg} / 100 \mathrm{~g}$ dry weight respectively.

As shows in Table 2, the organic and aqueous byproducts of four varieties of mango and one variety of peanut and pomegranate exhibited good antioxidant capacity as assessed by five antioxidant assays: DPPH, ABTS, inhibition of bleaching $\beta$-carotene/linoleic acid and FRAP. The results also revealed that all organic extracts among all by-products had more antioxidant efficient than that aqueous extracts. Moreover, among all by-products extracts, the total antioxidant capacities are vary considerably from one by-product to another, from one variety of mangos to another and in mango from part of (kernel seed and pulp seed) to others. Among all mango parts, seed pulp had the highest antioxidant activity than that found for seed kernel. This observation may be due to the highest values of phenolic contains in mango seed pulp than mango seed kernel (Table 2). The similar results are obtained by (Kalt, 2005; Ayala-Zavala et al., 2011). They reported that the phenolic compounds are located preferentially in peel and seeds and in a lesser extent in the flesh. Also, significant differences in antioxidant capacity were observed among different antioxidant assays, that all assays were used as complementary to evaluate the potential antioxidant activity. Dorta et al (2012) found that the good correlations between antioxidant activity of phenolic and anthocyanin compounds in mango peel or seed and these compounds played a major role in the antioxidant capacity. Ismail et al. (2012) mentioned that the free radical scavenging (antioxidant activity) activity of pomegranate phenolics due to electron donate to free radicals, that converts them to relatively more stable compounds. However, this antioxidant mechanism have confirmed as that reported for the antioxidant activity of plants extracts depends on the concentration of phenolic compounds (Farag et al., 1989). Naveena et al. (2008) found that antioxidant power of peel pomegranate had linearly correlation with increase the concentration of phenolics contained reach to the level of $400 \mathrm{mg} \mathrm{g}^{-1}$. In general, phenolic are the major plant compounds with high level of antioxidant activity, this activity could be due to their ability to adsorb, neutralize and to quench free radicals to protect the plant tissues against oxidative damage (Oyedemi et al., 2010; Duh et al., 1999). Here again, crude organic-extract of fruit by-products showed potential activity as tested by 5 antioxidant assays compared to synthetic antioxidants BHA. The natural antioxidant is preferred over synthetic antioxidants to minimize adverse effects on humankind. Therefore, it could be suggested that the organic extracts may exert a better function in free radical scavenging and a promising alternative to synthetic substances as natural compound with high-antioxidant activity.

The data of phenolic constituents among all by products extracts had about similar quality profile with varied quantity percentages. However, some phenolic compounds in mango variety could be use a marker for characterized of some varieties such as ferulic $(27.14 \%)$, vanillic $(24.75 \%)$ and mangiferin $(13.56 \%)$ for zibdia variety, caffeine $(17.87 \%)$, vanillic acid $(13.11 \%)$ and ferulic acid $(11.47 \%)$ for soccary variety and vanillic acid (15.67\%), caffeine $(15.67 \%)$, Benzoic acid $(13.18 \%)$ and mangiferin $(11.31 \%)$ for timor variety. These results revealed that mango seed pulp by products were characterized by present significant amounts of vanillic, ferulic, caffeine, mangiferin and chlorogenic acids. In general these data are agree with obtained by Abdalla et al. (2007), that the major phenolic compounds in mango seed kernel were 3,4dihydroxy benzoic acid, ellagic acid, mangiferin, isomangiferin, homomangiferin, O-p-hydrybenzoic acid. Also, Puravankara et al. (2000) detected six major phenolic compounds (mainly, gallic acid, ellagic acid and gallates) in dried mango seed kernel. However, Nunez-Selles (2005) reported that phenolic compounds were found in significant concentration in mango seed kernel and barks to be responsible for antioxidant activity. For phenolic constituents in kernel pomegranate fruits are diver than that reported by several researchers, that the major phenolic compounds were punicalagin, ellagic acid, gallo-tannins and anthocyanins (Kaplan et al., 2001; Noda et al., 2002; Cerda et al., 2003). However, the results agree with that the main phenolics in pomegranate were gallic and ellagic acids (Huang et al., 2005). The results of phenolic constituents in peanut shell are agreed with that obtained by (Talcott et al., 2005). However, p-hydroxybenzoic, chlorogenic, ferulic, caffeic and gallic are common phenolic acids found in peanuts (Win et al., 2011). 
The results of thermal stability of sunflower seed oil tested by rancemat method indicated that concentrations of organic and aqueous extracts $(0.01,0.02$ and $0.05 \%)$ for the fruits by-products under investigation were gradually increased the oil stability as indicate by increased induction period (time), with varied degree of the antioxidant effectiveness. An obviously differences were found between the pure oil as control and the oils containing extracts, which increase the induction period and stability as well as the auto-oxidation of oils was inhibited in the presence of mango seed both pulp and kernel organic extracts. Also, the aqueous extract of the four varieties of mango seed pulp and pomegranate were improving the stability of sunflower oil at level of 0.01 and it is considerable as potent antioxidant effectiveness. As the data in Table 4 showed the relative lower stability of sunflower oil mixed with aqueous extracts of mango and pomegranate at 0.05 levels (relative high concentration) may be due to the increase the level of antioxidant additive act as pro-oxidant or as antagonist agents (Olcott and Einest, 1957). Here again organicextract of tested by-products showed potential activities as antioxidant agents compared to standard synthetic antioxidants BHA. Since, the natural antioxidant is preferred over synthetic antioxidants to minimize adverse effects on humankind.

\section{CONCLUSION}

From aforementioned results, it can be concluded that the by-product parts of mango (kernel and pulp), pomegranate (kernel) and peanut (shell/skin) displayed high antioxidant activities and could be used safely in the edible oil industry to delay its auto-oxidation. It can be applied in pharmaceutical, cosmetic and food industries as a natural antioxidant instead of synthetic antioxidants. However, further biological studies are expected to show positive results of these extracts

\section{REFERENCES}

Abdalla, A.E.M., S.M. Darwish, E.H.E. Ayad and R.M. El-Hamahmy, 2007. Egyptian mango by-product 1. Compositional quality of mango seed kernel. J. Food Chem., 103: 1134-1140. DOI: 10.1016/j.foodchem.2006.10.017

Ajila, C.M., K.A. Naidu, S.G. Bhat and U.J.S. PrasadaRao, 2007a. Bioactive compounds and antioxidant potential of mango peel extract. Food Chem., 105: 982-988. DOI: 10.1016/j.foodchem.2007.04.052
Ajila, C.M., S.G. Bhat and U.J.S. Prasada-Rao, 2007b. Valuable components of raw and ripe peels from two Indian mango varieties. Food Chem., 102: 1006-1011. 10.1016/j.foodchem.2006.06.036

Ayala-Zavala, J.F., V. Vega-Vega, C. Rosas-Domínguez, H. Palafox-Carlos and J.A. Villa-Rodriguez et al., 2011. Agro-industrial potential of exotic fruit byproducts as a source of food additives. Food Res. Int. J., 44: 1866-1874. DOI: 10.1016/j.foodres.2011.02.021

Berardini, N., M. Knodler, A. Schieber and R. Carle, 2005. Utilization of mango peels as a source of pectin and polyphenolics. Innovative Food Sci. Emerg. Technol., 6: 442-452. DOI: 10.1016/j.ifset.2005.06.004

Brand-Williams, W., M.E. Cuvelier and C. Berset, 1995. Use of a free radical method to evaluate antioxidant activity. Lebensm Wiss, Technol., 28: 25-30. DOI: 10.1016/S0023-6438(95)80008-5

Cerda, B., J.J. Ceron, F.A. Tomas-Barberan and J.C. Espin, 2003. Repeated oral administration of high doses of the pomegranate ellagitannin punicalagin to rats for 37 days is not toxic. J. Agric. Food Chem., 51: 3493-3501. DOI: 10.1021/jf020842c

Costa, A.G.V., D.F. Garcia-Diaz, P. Jimenez and P.I. Silva, 2009. Bioactive compounds and health benefits of exotic tropical red-black berries. J. Funct. Foods, 5: 539-549. DOI: 10.1016/j.jff.2013.01.029

Demiray, S., M.E. Pintado and P.M.L. Castro, 2009. Evaluation of phenolic profiles and antioxidant activities of Turkish medicinal plants: Tilia argentea, Crataegi folium leaves and Polygonum bistorta roots. World Acad. Sci. Eng. Technol., 54: 312-317.

Djilas, S., J. C`anadanovic'-Brunet and G. C'etkovic', 2009. By-products of fruits processing as a source of phytochemicals. Chemical Industry Chemical Eng. Q., 15: 191-202. DOI: 10.2298/CICEQ0904191D

Duh, P.D., Y.Y. Tu and G.C. Yen, 1999. Antioxidant activity of water extract of harng jyur (Chrysanthemum morifolium Ramat). Lebensm Wiss Technol., 32: 269-277. DOI: 10.1006/fstl.1999.0548

Elleuch, M., D. Bedigian, O. Roiseux, S. Besbes and C. Blecker et al., 2011. Dietary fibre and fibre-rich byproducts of food processing: Characterisation, technological functionality and commercial applications: A review. Food Chem., 124: 411-421. DOI: 10.1016/j.foodchem.2010.06.077 
Dorta, E., M.G. Lobo and M. González, 2012. Using drying treatments to stabilise mango peel and seed: Effect on antioxidant activity. LWT-Food Sci. Technol., 45: 261-268. DOI: 10.1016/j.lwt.2011.08.016

Farag, R.S., A.Z.M. Badei, F.M. Hewadi and G.S. ELBaroty, 1989. Antioxidant activity of some spice essential oils on linoleic acid oxidation in aqueous media. Am. Oil. Chem. Soc., 66: 792-799. DOI: 10.1007/BF02653670

Gordon, M.H. and E.A. Mursi, 1994. A comparison of oil stability based on the Metrohm Rancimat with storage at $20^{\circ} \mathrm{C}$. JAOCS, 71: 649-651. DOI: 10.1007/BF02540595

Goupy, P., M. Hugues, P. Boivin and M.J. Amiot, 1999. Antioxidant composition and activity of barley (Hordeum vulgare) and malt extracts and of isolated phenolic compounds. J. Sci. Food Agric., 79: 16251634. DOI: 10.1002/(SICI)10970010(199909)79:12<1625::AIDJSFA411>3.0.CO;2-8

Hasenhuettl, G.L. and P.J. Wan, 1992. Temperature effects on the determination of oxidative stability with the metrohm rancimat. J. Am. Oil Chem. Society, 69: 525-527. DOI: 10.1007/BF02636102

Huang, T.H., G. Peng, B.P. Kota, G.Q. Li and J. Yamahara et al., 2005. Anti-diabetic action of Punica granatum flower extract: Activation of PPAR- $\gamma$ and identification of an active component. Toxicol. Applied Pharmacol., 207: 160-169. DOI: 10.1016/j.taap.2004.12.009

Ismail, T., P. Sestili and S. Akhtar, 2012. Pomegranate peel and fruit extracts: A review of potential antiinflammatory and anti-infective effects. J. Ethnopharmacol., 143: 397-405. DOI: 10.1016/j.jep.2012.07.004

Jahangir, M., H.K. Kim, Y.H. Choi and R. Verpoorte, 2009. Health-affecting compounds in brassicaceae. Compr. Rev. Food Sci. Food Saf., 8: 31-43. DOI: 10.1111/j.1541-4337.2008.00065.x

Jawad, A.H., A.F.M. Alkarkhi, O.C. Jason and A.M. Easa, 2013. Production of the lactic acid from mango peel waste-factorial experiment. J. King Saud Univ. Sci., 25: 39-45. DOI: 10.1016/j.jksus.2012.04.001

Kalt, W., 2005. Effects of production and processing factors on major fruit and vegetable antioxidants. J. Food Sci., 70: R11-R19. DOI: 10.1111/j.13652621.2005.tb09053.x
Kaplan, M., T. Hayek, A. Raz, R. Coleman and L. Dornfeld et al., 2001. Pomegranate juice supplementation to atherosclerotic mice reduces macrophage lipid peroxidation, cellular cholesterol accumulation and development of atherosclerosis. J. Nutrit., 131: 2082-2089.

Labulbi, M.W. and P.A. Bruttel, 1986. Determination of the oxidative stability of fats and oils: Comparison between the active oxygen method (AOCS Cd 1257) and the rancimat method. J. Am. Oil Chem. Society, 63: 792-795. DOI: 10.1007/BF02541966

Larrauri, J.A., P. Rupérez, B. Borroto and F. SauraCalixto, 1996. Mango peels as a new tropical fiber: Preparation and characterization. LWT-Food Sci. Technol., 29: 729-733. DOI: 10.1006/fstl.1996.0113

Lim, Y.Y. and J. Murtijaya, 2007. Antioxidant properties of Phyllanthus amarus extracts as affected by different drying methods. LWT-Food Sci. Technol., 40: 1664-1669. DOI: 10.1016/j.lwt.2006.12.013

Maisuthisakul, P., 2009. Antioxidant potential and phenolic constituents of mango seed kernel from various extraction methods. Kasetasart J. Natural Sci., 43: 290-297.

Nandeesh, K., R. Jyotsna and G. Venkateswara Rao, 2011. Effect of differently treated wheat bran on rheology, microstructure and quality characteristics of soft dough biscuits. J. Food Process. Preservat., 35: 79-200. DOI: $10.1111 /$ j. $1745-$ 4549.2009.00470.x

Naveena, B.M., A.R. Sen, R.P. Kingsly, D.B. Singh and N. Kondaiah, 2008. Antioxidant activity of pomegranate rind powder extract in cooked chicken patties. Int. J. Food Sci. Technol., 43: 1807. DOI: 10.1111/j.1365-2621.2007.01708.x

Noda, Y., T. Kaneyuki, A. Mori and L. Packer, 2002. Antioxidant activities of pomegranate fruit extract and its anthocyanidins: Delphinidin, cyanidin and pelargonidin. J. Agric. Food Chem., 50: 166-171. DOI: $10.1021 / \mathrm{jf0} 108765$

Nunez-Selles, A.J., 2005. Antioxidant therapy: Myth or reality? J. Brazilian Chemical Society, 16: 699-710. DOI: $10.1590 / \mathrm{S} 0103-50532005000500004$

Olcott, H. and E. Einset, 1957. A weighing method for measuring the induction period of marine and other oils. J. Am. Oil Chem. Society, 35: 161-162. DOI: 10.1007/BF02539872

Oyedemi, S.O., G. Bradley and A.J. Afolayan, 2010. In vitro and in vivo antioxidant activities of aqueous extract of Strychnos henningsii Gilg. Afr. J. Pharm. Pharmacol., 4: 70-78. 
Puravankara, D., V. Boghra and R.S. Sharma, 2000. Effect of antioxidant principles isolated from mango (Mangifera indica L.) seed kernels on oxidative stability of buffalo ghee (Butter-Fat). J. Sci. Food Agric., 80: 522-526. DOI: 10.1002/(SICI)1097-

0010(200003)80:4<522::AID-

JSFA560>3.0.CO;2-R

Re, R., N. Pellegrini, A. Proteggente, A. Pannala and M. Yang et al., 1999. Antioxidant activity applying an improved ABTS radical cation decolorization assay. Free Radical Biol. Med., 26: 1231-1237. DOI: 10.1016/S0891-5849(98)00315-3

Ribeiro-Junior, M.A., T.A. Gardner and T.S. Avila-Pires, 2008. Evaluating the effectiveness of herpetofaunal sampling techniques across a gradient of habitat change in a tropical forest landscape. J. Herpetol., 42: 733-749. DOI: 10.1670/07-097R3.1
Soong, Y.Y. and P.J. Barlow, 2004. Antioxidant activity and phenolic content of selected fruit seeds. Food Chem., 88: 411-417. DOI: 10.1016/j.foodchem.2004.02.003

Spanos, G.A. and R.E. Wrolstad, 1990. Influence of processing and storage on the phenolic composition of apple juice. J. Agrc. Food Chem., 38: 1565-1571. DOI: 10.1021/jf00097a031

Talcott, S.T., S. Passeretti, C.E. Duncan and D.W. Gorbet, 2005. Polyphenolic content and sensory properties of normal and high oleic acid peanuts. Food Chem., 90: 379-388. DOI: 10.1016/j.foodchem.2004.04.011

Win, M.M., A. Abdul-Hamid, B.S. Baharin, F. Anwar and M.S. Sabu et al., 2011. Phenolic compounds and antioxidant activity of peanut's skin, hull, raw kernel and roasted kernel flour. Pak. J. Bot., 43: 16351642. 